\title{
INFLUENCE OF LUTING RESIN CEMENT POLYMERIZATION MODE AND VENEER THICKNESS ON THE COLOR STABILITY OF FELDSPATHIC CAD/CAM VENEERS
}

\author{
Zeinab M. Morsy ${ }^{1}$ BDS, Mona M. Ghoneim² PhD, Rania R. Afifi ${ }^{3} \mathrm{PhD}$
}

\begin{abstract} clinical success of the restoration as the mechanical properties of the veneer. the color stability of feldspathic CAD/CAM veneers. different time intervals. statistically significant difference in $\Delta \mathrm{E} 2$ between groups IA and IB. ceramic thickness can serve to mask the underlying color change.

KEYWORDS: Porcelain laminate veneers, ceramic thickness, resin cement, Vita Easyshade.

RUNNING TITLE: Color stability of ceramic veneers.
\end{abstract}

INTRODUCTION: The color stability of the resin-based cement employed for the cementation procedure may be as important for the long-term

OBJECTIVES: The aim of this study was to evaluate the effect of different polymerization modes of resin cements and ceramic thicknesses on

MATERIALS AND METHODS: Sixty-four sound human maxillary central incisor teeth were divided according to ceramic veneer thickness used into two main groups ( $\mathrm{n}=32$ ); Group I; $0.5 \mathrm{~mm}$ ceramic thickness and Group II; $1 \mathrm{~mm}$ ceramic thickness, each group was then subdivided according to the type of resin cement received (Light cure LC or Dual cure DC) into four sub groups of 16 specimens each: Group I A:(0.5 + LC); Group I B:(0.5 + DC); Group II A:(1 + LC); Group II B $(1+D C)$. Sixty four Ceramic discs were prepared; for group I, 32 discs of diameter 7 mm and height $0.5 \mathrm{~mm}$ while for group II, 32 discs of diameter $7 \mathrm{~mm}$ and height $1 \mathrm{~mm}$. The shade was measured using digital spectrophotometer at 3

RESULTS: Ceramic thickness alone revealed statistically significant effect on the $\Delta \mathrm{E}$ values of all groups ( $\mathrm{p} \leq 0.05)$, irrespective of the type of the resin cement. The highest mean $\Delta \mathrm{E}$ values were recorded in group I $\mathrm{A}$ and the lowest $\Delta \mathrm{E}$ values were recorded in group II $\mathrm{B}$.There was

CONCLUSIONS: All studied cements showed $\triangle \mathrm{E}$ within clinically acceptable range in both dual cure and light cure resin cements. Increasing

${ }^{1}$ Master student of Operative Dentistry, Department of Conservative Dentistry, Faculty of Dentistry, Alexandria University, Egypt.

${ }^{2}$ Assistant Professor of Operative Dentistry, Department of Conservative Dentistry, Faculty of Dentistry, Alexandria University, Egypt.

${ }^{3}$ Lecturer of Operative Dentistry, Department of Conservative Dentistry, Faculty of Dentistry, Alexandria University, Egypt.

*Corresponding author:

E-mail: zaina_177@hotmail.com

\section{INTRODUCTION}

Laminate veneers are indirect restorations performed by conservative techniques with the purpose of harmonizing the smile, restoring the adequate color, shape and function of esthetically compromised teeth (1). With the great emphasis placed on esthetics by today's society, the color stability of esthetic restorative materials is gaining critical importance (2).

In the clinical condition, only the margin of the luting agent film of the ceramic veneers that are cemented to tooth structures is exposed to the oral environment, which may result in its discoloration. Discoloration of resin cements is a common problem, particularly in translucent restorations. In fact, color changes in the restorations and the surrounding tissues are the primary reasons for the replacement of esthetic restorations (3).

However, the success of clinical treatment is multifactorial and depends on the perfect combination of colors between the restoration and remaining teeth, the color of the supporting tooth substructure, thickness, shade and type of ceramic and resin cement. Moreover, the restorative material's translucency shown by the amount of reflection and scattering of light is another factor (4-7). Together with all-ceramic materials, resin-based cements are considered an essential part of the success and quality of esthetic treatments (8-9).

In the case of ultrathin restorations, such as ceramic veneers, the color stability of the resin-based cement employed for the cementation procedure may be as important for the long-term clinical success of the restoration as the mechanical properties of veneering material (10). The longevity of laminate veneer restoration is related to the material's color stability $(11,12)$ and the cementation technique $(13,14)$.

An important concern regarding the cementation step is to ensure optimal polymerization of the resin cement, since this influences its long-term color stability (15).

Adhesive technologies have improved significantly in the last few years, and both dual- and light-cure adhesive resins have been used as luting agents with porcelain laminate veneers (PLVs) (16-17). Light-curing materials used as luting agents are easily handled and are characterized by controllable hardening times and long-term color stability (4, $15,19,20)$. They also allow precise seating of the veneer and accurate removal of the excess cement. The dual-curing materials are advantaged by their self-curing component, 
which favors conversion even in the presence of scarce radiant energy (21). Recently, new resin cements without a benzoyl peroxide/amine redox initiator system have been shown to be more color- stable (22).

Considering the importance of the color stability of a porcelain laminate veneer (PLV) for its long-term success, the aim of the study was to evaluate the effect of different polymerization modes of resin cements on the color stability of feldspathic CAD/CAM veneers of different thicknesses.

The null hypothesis tested was that the mode of polymerization of luting resin cement and veneer thickness used will not affect the color stability of feldspathic $\mathrm{CAD} / \mathrm{CAM}$ veneers.

\section{MATERIALS AND METHODS}

The study was conducted after receiving the approval of the ethical committee at Faculty of Dentistry, Alexandria University, Egypt.

Sixty- four extracted human maxillary central incisor teeth were used to evaluate the effect of different modes of polymerization of resin cements and ceramic thicknesses on the color stability of ceramic veneers. Two resin cements Rely X Veneer (light cure) and Rely X ultimate (dual cure), (Ivoclar Vivadent, Schaan, Liechtenstein) - and glass-ceramic- IPS empress CAD (Ivoclar Vivadent, Schaan, Liechtenstein) - were selected for this study. The descriptions of the adhesives and the ceramic included in this study are summarized in (Table 1).

Selected teeth were free of caries, attrition, abrasion, cracking or previous restoration. The teeth were thoroughly debrided from all soft tissues or bone, and stored in chloramine solution at room temperature until use.

The root portion of all teeth was removed using carborundum discs, and the crown part was inserted into selfcuring acrylic resin using a custom made split metallic copper mold with a fixed diameter exposing the labial surface upwards. The 64 specimens were randomly divided according to ceramic thickness into two main groups of 32 specimens each; Group I represented $0.5 \mathrm{~mm}$ ceramic veneer thickness and Group II represented $1 \mathrm{~mm}$ ceramic veneer thickness, then each group was subdivided according to the type of adhesive resin cement used for cementation of the ceramic discs into four sub groups (Group I A, I B and Group II A, II B) of 16 specimens each.

Facial surfaces of the teeth were initially prepared by placing depth-orientation grooves $(0.5 \mathrm{~mm}$ in depth) with a depth preparation bur. (Microdont, Rodovia Fernao Dias, Sao Paulo, Brazil).Then, the specimens were prepared without exceeding the depth-orientation grooves to provide flat enamel surface area, $5 \mathrm{~mm}$ in diameter, measured by a periodontal probe , for luting the ceramic discs to the middle third of the facial surface.

A total of 64 Empress CAD ceramic discs were obtained from multilayered glass-ceramic blocks (IPS Empress CAD HT I12 A1) using a microtome precision cutter (Isomet TM 4000 linear precision saw, Buehler, USA), cutting at a speed of $350 \mathrm{rpm}$ with a water cooling unit attached to the cutter. For group I, 32 discs were obtained of thickness $0.5 \mathrm{~mm}$, diameter $7 \mathrm{~mm}$. (Figure 1) for group II, 32 discs were obtained of thickness $1 \mathrm{~mm}$, diameter $7 \mathrm{~mm}$. (Figure 2)
The ceramic discs were bonded to the prepared teeth, specimens of groups IA, IB were cemented with light cure resin cement (Rely $\mathrm{X}$ veneer resin cement), while specimens of groups II A, II B were cemented with dual cure resin cement (Rely x ultimate resin cement). The cementation was performed under a constant load of $2.0 \mathrm{kgs}$ for two minutes using a custom made static loading device to ensure uniform thickness of the cement during curing (custom made at Bio-Dental materials Department, Alexandria university).

The bonded specimens were thermocycled 1000 cycles between $5{ }^{\circ} \mathrm{C}$ and $55^{\circ} \mathrm{C}$ with a dwell time of 15 seconds at each temperature (16).

All specimens were submitted to color readings using a digital Spectrophotometer (Vita Easyshade; VITA Zahnfabrik, Bad Säckingen, Germany) against a white background at three different time intervals; after the preparation (only the tooth substrate), after the cementation and polymerization of the veneers and after the accelerated artificial ageing (AAA) process. (Figure 3)

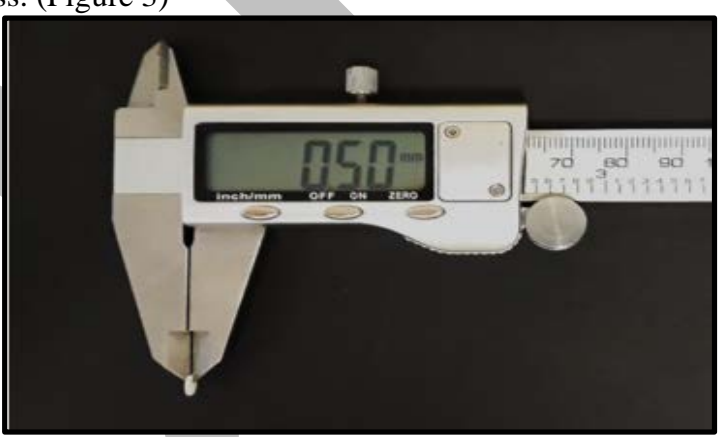

Figure (1): $0.5 \mathrm{~mm}$ thickness ceramic specimen

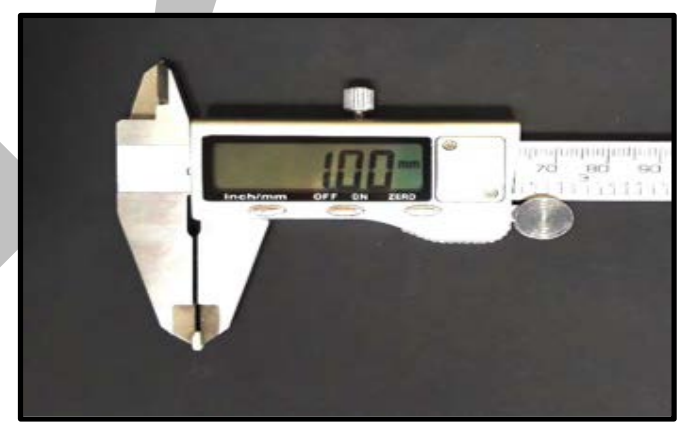

Figure (2): $1 \mathrm{~mm}$ thickness ceramic specimen

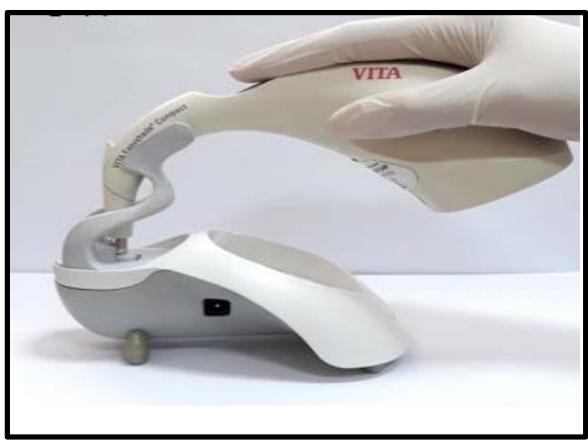

Figure (3): Calibration of Vita Easy Shade spectrophotometer against white background 
Table (1): Materials composition

\begin{tabular}{|c|c|c|}
\hline Brand name & Manufacturer & Composition \\
\hline $\begin{array}{l}\text { IPS empress } \\
\text { CAD } \\
\text { (Shade A1) }\end{array}$ & $\begin{array}{l}\text { Ivoclar } \\
\text { Vivadent, } \\
\text { Liechtenstein }\end{array}$ & $\begin{array}{ll}\text { - } \mathrm{SiO} 2 & 60.0-65.0 \% \text { by wt } \\
\text { - } \mathrm{Al} 2 \mathrm{O} 3 & 16.0-20.0 \% \text { by wt } \\
\text { - } \mathrm{K} 2 \mathrm{O} & 10.0-14.0 \% \text { by wt } \\
\text { - } \mathrm{Na} 2 \mathrm{O} & 3.5-6.5 \% \text { by wt } \\
\text { - Other oxides } & 0.5-7.0 \% \text { by wt } \\
\text { - Pigments } & 0.2-1.0 \% \text { by wt } \\
\text { - } 1-5 \mu \mathrm{m} \text { leucite crystals } \\
\text { (35-45\% by volume) }\end{array}$ \\
\hline $\begin{array}{l}\text { Rely X } \\
\text { Veneer }\end{array}$ & $\begin{array}{l}\text { 3M } \\
\text { Deutschland, } \\
\text { Neuss, } \\
\text { Germany }\end{array}$ & $\begin{array}{l}\text { - Silane--treated ceramic (55-56\% byWt) } \\
\text { - TEGDMA (triethylene glycol } \\
\text { dimethacrylate) (10-20-\% by wt) } \\
\text { - bisphenol a diglycidyl ether } \\
\text { dimethacrylate (BISGMA)(10-2-\% by } \\
\text { wt) } \\
\text { - silane treated silica(1-10\% by wt) } \\
\text { - reacted polycarpolactone polymer(1- } \\
10 \% \text { by wt) } \\
\text { - titanium dioxide(<1\% by wt) } \\
\text { - diphenyliodoniumhexafluorophosphate } \\
\text { - Triphenylantimony }\end{array}$ \\
\hline $\begin{array}{l}\text { Rely X } \\
\text { Ultimate }\end{array}$ & $\begin{array}{l}\text { 3M } \\
\text { Deutschland, } \\
\text { Neuss, } \\
\text { Germany }\end{array}$ & $\begin{array}{l}\text { Base paste: } \\
\text { Silane--treated glass powder (50-60\% by } \\
\text { Wt) modified with } \\
\text { 2-propenoic acid ( } 20-30 \% \text { by Wt),2- } \\
\text { methyl-, reaction products with 2- } \\
\text { hydroxy-1,3-propanedyl dimethacrylate } \\
\text { and phosphorus oxide, TEGDMA } \\
\text { (triethylene glycol dimethacrylate) (10- } \\
\text { 20-\% by Wt), silane--treated silica, }(1-1- \\
\text { \% byWt),Oxide glass chemicals ( }<3 \% \\
\text { bywt), sodium persulfate (<1\%by } \\
\text { Wt),Tertbutyl peroxy-3,5,5- } \\
\text { trimethylhexanoate ( } 0.25 \% \text { byWt),copper } \\
\text { acetate monohydrate(0.1\% by Wt) } \\
\text { Catalyst paste } \\
\text { Silane-treated glass powder, substituted } \\
\text { dimethacrylate,1,12-dodecane } \\
\text { dimethacrylate, silane--treated silica1- } \\
\text { benzyl-5-phentyl-barbic-acid, calcium } \\
\text { salt, sodium p-toluenesulfinate, 2- } \\
\text { propenic acid, 2-methyl-, di-2,1- } \\
\text { ethanediyl ester, calcium hydroxide, } \\
\text { titanium dioxide. }\end{array}$ \\
\hline
\end{tabular}

The color was evaluated according to the color system CIE La*b* (The LAB color model is a three axis color system where $\mathrm{L}$ axis represents lightness, $\mathrm{a}^{*}$ axis goes from red to green, $b^{*}$ axis goes from yellow to blue) (28).

The difference in color was expressed as $\Delta \mathrm{E}$ and is measured by the following equation (25).

$\Delta \mathrm{E}^{*}=\left[\left(\Delta \mathrm{L}^{*}\right)^{2}+\left(\Delta \mathrm{a}^{*}\right)^{2}+\left(\Delta \mathrm{b}^{*}\right)^{2}\right]^{1 / 2}$; where $\Delta \mathrm{L}^{*}$ is the variation of $\mathrm{L}^{*}, \Delta \mathrm{a}^{*}$ is the variation of $\mathrm{a}^{*}$, and $\Delta \mathrm{b}^{*}$ is the variation of $b^{*}$

\section{Statistical analysis of the data}

Data were fed to the computer and analyzed using IBM SPSS software package version 20.0. (Armonk, NY: IBM Corp). The Kolmogorov-Smirnov test was used to verify the normality of distribution. Quantitative data were described using range (minimum and maximum), mean, standard deviation and median. Significance of the obtained results was judged at the $5 \%$ level.

\section{The used tests were}

\section{1 - Student t-test}

For normally distributed quantitative variables, to compare between two studied groups

\section{2 - F-test (ANOVA)}

For normally distributed quantitative variables, to compare between more than two groups, and Post Hoc test (Tukey) for pairwise comparisons

\section{3 - Two way (ANOVA)}

Was used to assess the effect of each factor and the interaction between them

\section{RESULTS}

By using Post Hoc test (Tukey) and Anova test for pairwise comparison between each 2 studied groups, it was found that light-cure resin cements showed lower $\Delta \mathbf{E}$ values than dual cure resin cements in all studied intervals. Although there was no significant difference between the two resin cements in all studied intervals at $1 \mathrm{~mm}$ thickness.

On comparing between types of resin cement (light cure/dual cure) used in each subgroup. Regarding $\Delta \mathrm{E} 1$, the highest mean $\Delta \mathrm{E}$ was recorded in group IA (Dual cure $+0.5 \mathrm{~mm}$ ) $14.67 \pm 1.80$, followed by group IB (Light cure $+0.5 \mathrm{~mm}$ ) $13.74 \pm 1.99$, then group IIA (Dual cure $+1 \mathrm{~mm}$ ) $9.11 \pm 1.07$, and the lowest $\Delta \mathbf{E} 1$ was recorded in group IIB (Light cure $+1 \mathrm{~mm}$ ) $8.42 \pm 1.32$. There was no statistically significant difference in $\Delta \mathbf{E} 1$ between groups IA and IB (p1=0.358), and no statistically significant difference between groups II A and II B (p4=0.613); However statistical significance was found between group IB and IIB $(\mathrm{p} 3<0.001)$ as well as between group IA and IIA (p2<0.001) (Table 2).

Table (2): Comparison between the different studied groups according to $\triangle \mathrm{E} 1$

\begin{tabular}{|c|c|c|c|c|c|c|}
\hline & $\begin{array}{c}\text { Group IA } \\
(\mathbf{n}=16)\end{array}$ & $\begin{array}{c}\text { Group IB } \\
(\mathrm{n}=16)\end{array}$ & $\begin{array}{c}\text { Group IIA } \\
(n=16)\end{array}$ & $\begin{array}{c}\text { Group IIB } \\
(\mathrm{n}=16)\end{array}$ & $\mathbf{F}$ & $\mathbf{p}$ \\
\hline $\begin{array}{c}\Delta \mathbf{E 1} \\
\text { Min. }- \text { Max. } \\
\text { Mean } \pm \text { SD. } \\
\text { Median }\end{array}$ & $\begin{array}{c}10.73-10.73 \\
13.74 \pm 1.99 \\
13.61\end{array}$ & $\begin{array}{c}11.64-17.81 \\
14.67 \pm 1.80 \\
15.07\end{array}$ & $\begin{array}{c}6.09-10.80 \\
8.42 \pm 1.32 \\
8.58\end{array}$ & $\begin{array}{c}7.29-10.77 \\
9.11 \pm 1.07 \\
9.18\end{array}$ & $63.717^{*}$ & $<0.001^{*}$ \\
\hline $\begin{array}{l}\text { Sig. bet. } \\
\text { grps }\end{array}$ & \multicolumn{4}{|c|}{$\mathrm{p}_{1}=0.358, \mathrm{p}_{2}<0.001^{*}, \mathrm{p}_{3}<0.001^{*}, \mathrm{p}_{4}=0.613$} & & \\
\hline \multicolumn{7}{|c|}{ 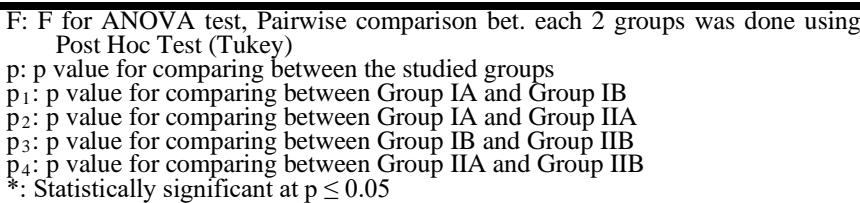 } \\
\hline
\end{tabular}

On comparing between types of resin cement (light cure/dual cure) used in each subgroup. Regarding $\Delta \mathrm{E} 2$,the highest mean delta $\mathrm{E}$ was recorded in group I A (Dual cure $+0.5 \mathrm{~mm}$ ) $3.15 \pm 0.40$, followed by group IB (Light cure $+0.5 \mathrm{~mm}$ ), $2.45 \pm 0.42$ then group II A (Dual cure $+1 \mathrm{~mm}$ ), 2.06 \pm 0.34 and the lowest $\Delta \mathrm{E} 2$ was recorded in group II B (Light cure $+1 \mathrm{~mm}) 1.89 \pm 0.42$. There was no statistically significant difference in $\Delta \mathbf{E} 2$ between groups IIA and II B (p4=0.618). However statistical significance was found between group IA and IB $(\mathrm{p} 1<0.001)^{*}$, as well as between group IA and IIA p $2<0.001$ and between groups IB and IIB (p3=0.001) (Table 3). 
Table (3): Comparison between the different studied groups according to $\triangle \mathrm{E} 2$

\begin{tabular}{|c|c|c|c|c|c|c|}
\hline & $\begin{array}{c}\text { Group IA } \\
(\mathrm{n}=16)\end{array}$ & $\begin{array}{c}\text { Group IB } \\
(\mathrm{n}=16)\end{array}$ & $\begin{array}{c}\text { Group IIA } \\
(\mathrm{n}=16)\end{array}$ & $\begin{array}{c}\text { Group IIB } \\
(\mathrm{n}=16)\end{array}$ & $\mathbf{F}$ & $\mathbf{p}$ \\
\hline$\Delta \mathrm{E} 2$ & & & & & & \\
\hline Min.-Max. & $1.71-3.28$ & $2.13-3.77$ & $0.71-2.42$ & $1.0-2.55$ & & \\
\hline $\begin{array}{c}\text { Mean } \pm \\
\text { SD. }\end{array}$ & $2.45 \pm 0.42$ & $3.15 \pm 0.40$ & $1.89 \pm 0.42$ & $2.06 \pm 0.34$ & $31.701^{*}$ & $<0.001^{\prime}$ \\
\hline Median & 2.31 & 3.15 & 2.01 & 2.17 & & \\
\hline \begin{tabular}{|c|} 
Sig. bet. \\
Grps \\
\end{tabular} & \multicolumn{4}{|c|}{$\mathrm{p}_{1}<0.001^{*}, \mathrm{p}_{2}<0.001^{*}, \mathrm{p}_{3}=0.001^{*}, \mathrm{p}_{4}=0.618$} & & \\
\hline \multicolumn{7}{|c|}{$\begin{array}{l}\text { F: F for ANOVA test, Pairwise comparison bet. each } 2 \text { groups was done using } \\
\text { Post Hoc Test (Tukey) } \\
\text { p: p value for comparing between the studied groups } \\
\mathrm{p}_{1}: \text { p value for comparing between Group IA and Group IB } \\
\mathrm{p}_{2}: \text { p value for comparing between Group IA and Group IIA } \\
\mathrm{p}_{3}: \text { p value for comparing between Group IB and Group IIB }\end{array}$} \\
\hline
\end{tabular}

On comparing between types of resin cement (light cure/dual cure) used in each subgroup. Regarding $\Delta \mathrm{E} 3$, the highest mean delta $\mathrm{E}$ was recorded in group I A (Dual cure $+0.5 \mathrm{~mm}$ ) $11.95 \pm 1.85$, followed by group IB (Light cure $+0.5 \mathrm{~mm}), 11.94 \pm 2.65$ then group II A (Dual cure $+1 \mathrm{~mm}$ ) $7.58 \pm 1.23$, and the lowest $\Delta \mathrm{E}$ was recorded in group $\mathbf{I I} \mathbf{B}$ (Light cure $+1 \mathrm{~mm}$ ) $4.89 \pm 1$.28. There was no statistically significant difference in $\triangle \mathrm{E} 3$ between groups IIA and II B (p4=0.817) as well as groups IA and IB (p1=1.000). However statistical significance was found between group IA and IIA (p2<0.001) as well as between groups IB and IIB $(\mathrm{p} 3<0.001)$.

\section{DISCUSSION}

A requirement for successful esthetics of ceramic restorations over the years is its color stability. In general, laminate veneer restorations are relatively thin and reflect the color of the cement. However the final color of translucent ceramic restoration is influenced by several factors such as ceramic type, color of underlying tooth structure and more importantly the luting cement type and ceramic thickness (2).

The results of the study indicate that the first hypothesis was partially accepted, it could be said that amine free dual cure resin cements performed as well as light-cured cements in terms of color stability. The results of the study indicate that the second hypothesis was rejected because the restoration thickness was a significant factor for color stability of feldspathic veneers.

The type of substructure of a translucent restoration may influence the color readout. In the present study, color readouts were taken before and after aging, so the substrate would not interfere in the final color results (23).

In this study, samples 0.5 and $1.0 \mathrm{~mm}$ thick were used; it is known that a standard laminate thickness is $0.7 \mathrm{~mm}$ (24). However, in a clinical situation, it is not always possible to get laminates of that exact measure, so it was considered important to foresee what would happen with greater or lesser thicknesses.

The Vita Easyshade compact digital spectrophotometer was used as a standard quantifying device for measuring color difference, it uses the $\Delta \mathrm{E}$ from the Commission International d'Eclairage CIE (L*a*b*) color system. Some researchers reported that a unit of color difference in CIE $\mathrm{L}^{*} \mathrm{a}{ }^{*} \mathrm{~b}$ color system is a visual color change which can be detected with human eye $(6,15)$. On the other hand, there are several opinions in literature about the threshold value for a clinically acceptable and visual color difference. This value is reported over $3.33(6,16-19), 3.5$ (15) or 3.7 (20). We adopted the threshold value of 3.5 for clinically accepted color difference when interpreting the results of this study.

In this study, 1000 cycles were used to represent a year of aging, this is similar to the work of Diamantopoulou et al (25) where he suggested that 1500 thermal cycles would be similar in physiologic normal conditions to the period of 1 and a half of year for resins. For the thermocycling process the temperature regimen of $50-550 \mathrm{C}$ proposed in ISO 11405 recommendations (International Standards Organization, 1994) was used in this study (26), dwell time of 30 seconds was chosen similar to other studies.

Both the dual and light-cured resin cements presented higher $\Delta \mathbf{E} 1 \Delta \mathbf{E 2}, \Delta \mathbf{E} 3$ values (i.e greater color change) when used for bonding $0.5 \mathrm{~mm}$ veneers in all studied intervals, with statistically significant difference $(\mathrm{p}<0.05)$ in comparison with the $1.0 \mathrm{~mm}$ thick veneer. Previous studies showed that in order to cover the color changes of the underlying cement, the ceramic thickness should be at least $2 \mathrm{~mm}(27,28)$. Nevertheless, based on the results of the present study, $1 \mathrm{~mm}$ thickness of feldspathic porcelain veneer serves to mask the color change of the underlying cement since the opacity of ceramic increases with increased thickness.

Our findings are in corroboration with the study of, Archegas et al. (29) and Alqahtani et al. (30) who concluded that $0.7 \mathrm{~mm}$ thickness produces a better masking effect when compared to $0.5 \mathrm{~mm}$ thickness. Thus the results of the present study support the rejection of the second null hypothesis that ceramic thickness does not influence the color stability of feldspathic veneers.

Regarding $\Delta \mathbf{E} 1$, representing the period immediately after cementation, results of the current study showed significant detectable color changes $(\Delta \mathbf{E} 1>3.3)$ for both RelyX Ultimate and rely $\mathrm{x}$ veneer composite resin cements regardless of ceramic thickness. However there was no significant difference between the two resin cements at same thickness. These results are consistent with the study of Qahtani et al (30), which concluded that restoration with veneers results in the final color. These results could be justified by the fact that most of the color changes of the resin cement occur during the first 24 hours of polymerization.

After aging of the tooth ceramic specimens, represented in this study as $\Delta \mathbf{E 2}$, color changes were evident in all groups regardless of restoration thickness, however all within clinically acceptable range $(<3.3)$. As expected, light cured resin cements showed lower $\Delta \mathbf{E}$ values in comparison with the dual cure resin cements. These findings are in accordance with the results of Smith et al, (31) who showed that resin cements lacking benzoyl peroxide and an amine redox initiator system are more color stable.

However, statistically significant difference was evident between the two resin cements at $0.5 \mathrm{~mm}$ thickness with slightly lower values for the light cure resin cement. This 
could be explained by the fact that light cure cements contain aliphatic amines in their structure which over time, is more color stable compared to dual- cured cements.

Our study has similar findings to Silami et al (32) who concluded that the thickness of the restoration influences color and luminosity changes for conventional dual and light-cured cements, however, in their study there was significant difference between the cements at 0.5 and $1 \mathrm{~mm}$ thickness.

This comes in opposition to the studies of Almeida et al (33), Hao Yu et al (34) stating that dual cure resin cements show inferior color stability. However, we found in their studies that the dual cure resin cement tested contains aromatic amine responsible for the color shift. Dual polymerizing cements have tertiary amines in their composition that act as chemical initiators for the polymerization reaction. For this reaction to occur, oxidation of the amine reactive groups is necessary and this may cause color changes (16). These materials contain a combination of different amines. One amine reacts with benzoyl peroxide (chemical polymerization/redox polymerization reaction) that is generally aromatic and more prone to degradation and another amine reacts with camphorquinone (light polymerizing). The latter is usually aliphatic and chemically more stable. In the chemical reaction, the unreacted benzoyl peroxide may also cause color instability $(15,16,23)$.

Our results are supported by Ghavam el al.(35), and Magalhaes et al (36) who had similar results and statistical findings to the ones in our study, where the color content of the resin\ceramic specimens was measured, and a conclusion that there were no significant differences (after artificial accelerated aging) between dual- and light-cured modes of both cements like in our study where all of the resin cements showed a $\Delta \mathrm{E}$ that remained in the range of clinical acceptance, although in our study there was a significant statistical difference between the dual and light cured groups in $0.5 \mathrm{~mm}$ thickness.

Also, Lucia et al (37) and Nijad et al (38) had similar findings to the ones in our study that most color variations occurred in the first 24 hours of polymerization, with relatively nonsignificant variations afterwards.

Also, Mesbah et al (39) concluded that the Rely X Ultimate (dual cured) resin cement could be used to cement veneers with a high final esthetic outcome and color stability like that of the light cured resin cements, however, contrary to our study the dual cure resin cements showed lower delta e values compared to light cured cements.

Thus, the first null hypothesis can be accepted. In agreement with the findings of Alkurt et al (40), it can be said that dual-curing resin cements performed as well as light curing resin cements within the limitations of this study.

The results of this study demonstrated that the effect of ceramic thickness on the color stability of veneers was much higher than the effect of the resin cement type, according to the results of the statistical analysis of the tested resin cements, there was no significant difference between the 2 different resin cements on comparing between groups of same thickness

\section{CONCLUSION}

1) The color changes of both light- and dual-cure resin cements were within clinically acceptable limits.
2) Although light cure resin cements had lower $\Delta \mathrm{E}$ values than dual cure cements, the difference was not significant.

3) Increasing ceramic thickness serves to mask the underlying color change.

\section{CONFLICT OF INTREST}

The authors declare that they have no conflicts of interest.

\section{REFERENCES}

1. Azzaldeen A, Muhamad AH. Restoration of Esthetics using Ceramics Laminate Veneer; Clinical Review: A Case Report. J Adv Med Dent Scie Res. 2015;3:180-5.

2. Tekçe N, Tuncer S, Demirci M, Serim ME, Baydemir C. The effect of different drinks on the color stability of different restorative materials after one month. Restor Dent Endod. 2015;40:255-61.

3. Shiozawa M, Takahashi H, Asakawa Y, Iwasaki N. Color stability of adhesive resin cements after immersion in coffee. Clin Oral Investig. 2015;19:309-17.

4. Alqahtani MQ, Aljurais RM, Alshaafi MM. The effects of different shades of resin luting cement on the color of ceramic veneers. Dent Mater J. 2012;31:354-61.

5. Abu-Izze FO, Piva D, Amanda MO, Bottino MA, Valandro LF, Melo RM. The Influence of Ceramic Repressing on Surface Properties, Bond Strength, and Color Stability of Leucite Ceramic. J Adhes Dent. 2018;20:38995.

6. Awad D, Stawarczyk B, Liebermann A, Ilie N. Translucency of esthetic dental restorative CAD/CAM materials and composite resins with respect to thickness and surface roughness. J Prosthet Dent. 2015;113:534-40.

7. Wang F, Takahashi H, Iwasaki N. Translucency of dental ceramics with different thicknesses. J Prosthet Dent. 2013;110:14-20.

8. Perroni AP, Kaizer MR, Della Bona A, Moraes RR, Boscato N. Influence of light-cured luting agents and associated factors on the color of ceramic laminate veneers: A systematic review of in vitro studies. Dent Mater. 2018;34:1610-24.

9. Kömürcüoğlu MB, Sağırkaya, E, Tulga, A. Influence of different surface treatments on bond strength of novel CAD/CAM restorative materials to resin cement. J Adv Prosthodont. 2017;9:439-46.

10. Pissaia JF, Correr GM, Gonzaga CC, Cunha LF. Influence of shade, curing mode, and aging on the color stability of resin cements. Br J Oral Sci. 2015;14:272-5.

11. Silami FD, Tonani R, Alandia-Román CC, Pires-deSouza FD. Influence of different types of resin luting agents on color stability of ceramic laminate veneers subjected to accelerated artificial aging. Braz Dent J. 2016;27:95-100.

12. Turgut S, Bagis B. Colour stability of laminate veneers: an in vitro study. J Dent. 2011;39:57-64.

13. Sari T, Ural C, Yüzbasioglu E, Duran I, Cengiz S, Kavut I. Color match of a feldspathic ceramic CAD-CAM material for ultrathin laminate veneers as a function of substrate shade, restoration color, and thickness. J Prosthet Dent. 2018;119:455-60. 
14. Hitz T, Stawarczyk B, Fischer J, Hämmerle CH, Sailer I. Are self-adhesive resin cements a valid alternative to conventional resin cements? A laboratory study of the long-term bond strength. Dent Mater. 2012;28:1183-90.

15. Rodrigues RB, Lima ED, Roscoe MG, Soares CJ, Cesar PF, Novais VR. Influence of resin cements on color stability of different ceramic systems. Braz Dent J. 2017;28:191-5.

16. Elgergawi M, Hassan RM. Influence of Cement Type on the Color Stability of Aged Laminate Veneer Ceramics of Two Different Thicknesses. EC Dent Sci. 2019;18:461-9.

17. AlShaafi MM. Factors affecting polymerization of resinbased composites: A literature review. Saudi Dent J. 2017;29:48-58.

18. Seyed MF, Somayeh Z, Yasamin BH. InvMain Factors Affecting the Final Color of Ceramic Restorations. Adv Dent Oral Health. 2017;5:555-661.

19. Jang Y, Ferracane JL, Pfeifer CS, Park JW, Shin Y, Roh B. Effect of insufficient light exposure on polymerization kinetics of conventional and self-adhesive dual-cure resin cements. Operative Dent. 2017;42:E1-9.

20. Alqahtani FI. Effect of newly developed resin cements and thermocycling on the strength of porcelain laminate veneers. J Contemp Dent Pract. 2017;18:209-13.

21. Murillo-Gómez F, Rueggeberg FA, De Goes MF. Shortand long-term bond strength between resin cement and glass-ceramic using a silane-containing universal adhesive. Operative Dent. 2017;42:514-25.

22. Smith DS, Vandewalle KS, Whisler G. Color stability of composite resin cements. Gen Dent. 2011;59:390-4.

23. Boaro LC, Gonçalves F, Guimarães TC, Ferracane JL, Pfeifer CS, Braga RR. Sorption, solubility, shrinkage, and mechanical properties of "low-shrinkage" commercial resin composites. Dent Mater. 2013;29:398404.

24. Cakan U, Kara HB. Effect of liquid polishing materials on the stainability of bis-acryl interim restorative materials in vitro. J Prosthet Dent. 2015;113:475-9.

25. Diamantopoulou S, Papazoglou E, Margaritis V, Lynch CD, Kakaboura A. Change of optical properties of contemporary resin composite after one week and one month water ageing. J Dent. 2013;41:62-9.

26. Gale MS, Darvel BW. Thermal cycling procedures for laboratory testing of dental restorations. J Dent. 1999;27:89-99.

27. Wang F, Takahashi H, Iwasaki N. Translucency of dental ceramics with different thicknesses. J Prosthet Dent. 2013;110:14-20.
28. Stevenson B, Ibbetson R. The effect of the substructure on the colour of samples/restorations veneered with ceramic: a literature review. J Dent. 2010;38:361-8.

29. Archegas LR, Freire A, Vieira S, Caldas DB, Souza EM. Colour stability and opacity of resin cements and flowable composites for ceramic veneer luting after accelerated ageing. J Dent. 2011;39:804-10.

30. Alqahtani MQ, Aljurais RM, Alshaafi MM. The effects of different shades of resin luting cement on the color of ceramic veneers. Dent Mater J. 2012;31:354-61.

31. Smith DS, Vandewalle KS, Whisler G. Color stability of composite resin cements. Gen Dent. 2011;59:390-4.

32. Silami FD, Tonani R, Alandia Roman CC, Pires-de Souza F de C. Influence of different types of resin luting agents on color stability of ceramic laminate veneers subjected to accelerated artificial aging. Braz Dent J. 2016;27:95-100.

33. Almeida JR, Schmitt GU, Kaizer MR, Boscato N, Moraes RR. Resin-based luting agents and color stability of bonded ceramic veneers. J Prosthet Dent. 2015;114:272-7.

34. Yu H, Cheng SL, Jiang NW, Cheng H. Effects of cyclic staining on the color, translucency, surface roughness, and substance loss of contemporary adhesive resin cements. J Prosthet Dent. 2018;120:462-9.

35. Ghavam M, Amani-Tehran M, Saffarpour M. Effect of accelerated aging on the color and opacity of resin cements. Oper Dent. 2010;35:605-9.

36. Magalhães AP, Cardoso Pde C, de Souza JB, Fonseca RB, Pires-de-Souza Fde C, Lopez LG. Influence of activation mode of resin cement on the shade of porcelain veneers. J Prosthodont. 2014;23:291-5.

37. Prieto LT, Pimenta de Araújo CT, AraujoPierote JJ, Salles de Oliveira DCR, Coppini EK, SartiniPaulillo LAM. Evaluation of degree of conversion and the effect of thermal aging on the color stability of resin cements and flowable composite. J Conserv Dent. 2018;21:47-51.

38. Mina NR, Baba NZ, Al-Harbi FA, Elgezawi MF, Daou M. The influence of simulated aging on the color stability of composite resin cements. J Prosthet Dent. 2019;121:306-10.

39. Mesbah MA, Morsi ST, Sabet EA. Assessment of color stability of different resin cements having different modes of polymerization before and after aging. J Am Sci. 2016;12:45-51.

40. Alkurt M, Duymus YZ. Comparison to color stability between amine with benzoyl peroxide includes resin cement and amine-reduced, amine-free, lacking of benzoyl peroxide resin cements after thermocycle. J Adv Oral Res. 2018;9:24-30. 